\title{
A Case Report of Gemella haemolysans Keratitis After Refractive Surgery
}

\author{
Yaohua Zhai \\ Chenjiu Pang \\ Shengtao Sun \\ Qiufei Ma \\ Lei Han \\ Yuwei Gu \\ Lizhe Gu
}

Henan Provincial People's Hospital, Henan Eye Hospital, Henan Eye Institute, Zhengzhou, 450003, People's Republic of China

Correspondence: Chenjiu Pang Email Pangcj999@I26.com
Purpose: Systematic review of Gemella haemolysans infection associated with ophthalmology, and to summarize the clinical characteristics of Gemellahaemolysans keratitis after refractive surgery.

Methods: Case report and literature review.

Results: We report an 18-year-old man who developed corneal infection after Trans-PRK, and the culture results of lesion specimens confirmed $G$. haemolysans keratitis. He was treated with fortified topical antibiotics, and clinical improvement was noted shortly after treatment. Resolution of keratitis was achieved at 1 month. Then, a systematic review of the reported cases of ocular $G$. haemolysans infection was conducted. We summarized clinical manifestations of $G$. haemolysans infection in cornea.

Conclusion: We reported a case of $G$. haemolysans keratitis infection after refractive surgery, and reviewed the literature of ocular G. haemolysans infection.

Keywords: trans-PRK, refractive surgery, postoperative infection, Gemella haemolysans, bacterial keratitis

The advantages of excimer laser corneal surface refractive surgery has the advantages of safety, reliability, good stability, recovery of corneal nerve and perceptual speed, with fewer postoperative dry eye symptoms. ${ }^{1,2}$ Trans-PRK, a new type of surface operation which has been widely used, could reduce the mechanical steps to remove the epithelium. Compared to laser in situ keratomileusis (LASIK), the trans-PRK-induced higher-order aberration of surgical origin was smaller, and its corneal biomechanical stability was better. However, the early loss of corneal epithelium and the use of glucocorticoids may increase the risk of corneal infection. Literature reports showed that common bacteria that could cause infectious keratitis after surgery included staphylococcus, streptococcus, and mycobacterium. ${ }^{3,4}$ So far, no cases of Gemella haemolysans bacterial keratitis after refractive surgery have been reported. To the best of our knowledge, this is the first case of Gemella haemolysans bacterial keratitis after trans-PRK with successful management.

\section{Case Report}

On January, 2020, an 18-year-old male patient had trans-PRK surgery in the local hospital due to myopia. The preoperative visual acuity of his eyes were 1.6/20 and 1.6/20, respectively. And there were no surgical contraindications. $0.5 \%$ levofloxacin eye drops 4 times a day and $0.1 \%$ sodium hyaluronate eye drops 4 times a day were routine applied three days prior to surgery. ${ }^{5}$ And the postoperative application was $0.5 \%$ levofloxacin eye 
drops 4 times a day, $0.1 \%$ sodium hyaluronate eye drops 4 times a day, and $0.1 \%$ flumilon eye drops 4 times a day. ${ }^{5}$ On the 4 th day after the operation, the left eye was sore and red and his vision reduced compared to prior to surgery. When the patient returned to the local hospital, the visual acuity of his right and left eye were 12/20 and 10/20, respectively. Epithelium of the right eye mostly healed but partly curled above the cornea. Cloudy central cornea was observed in his left eye and infectious keratitis was considered. Afterwards, he was given $0.5 \%$ levofloxacin eye drops every 30 minutes, lincomycin eye drops every 30 minutes, $0.1 \%$ sodium hyaluronate eye drops 4 times a day, levofloxacin gel 1 time each night, and polytropicamide eye drops twice a day. Nevertheless, the symptoms were not improved after a two-day-long treatment. On the 6th day after the operation, he was transferred to our hospital for further treatment. The visual acuities of his right eye and left eye were
$12 / 20$ and 10/20. Optometric visual acuity of the right eye $-1.00 \mathrm{ds}-1.0$ but the left eye could not be corrected. Slit-lamp examination revealed the cornea of the right eye transparent and the anterior chamber normal, but the upper corneal epithelium was poorly healed (Figure 1A). In the left eye, mixed congestion of the bulbar conjunctiva and corneal edema were witnessed. Moreover, corneal endodermis, Descemet's folds and sediments adhering to the endodermis white infiltrating foci with crab-like changes and unclear observed boundary was observed in the center of corneal, with an annular reaction ring, corneal endodermis, Descemet's folds and sediments adhering to the endodermis (Figure 1B). Oct-optic (cassia) of the left eye revealed that the central cornea was swollen and cloudy up to a depth of $1 / 2$ (Figure 2). Confocal microscopy of the left eye indicated epithelial cells necrotic and absent (Figure 3A), the stromal layer turbid and edema, endothelium

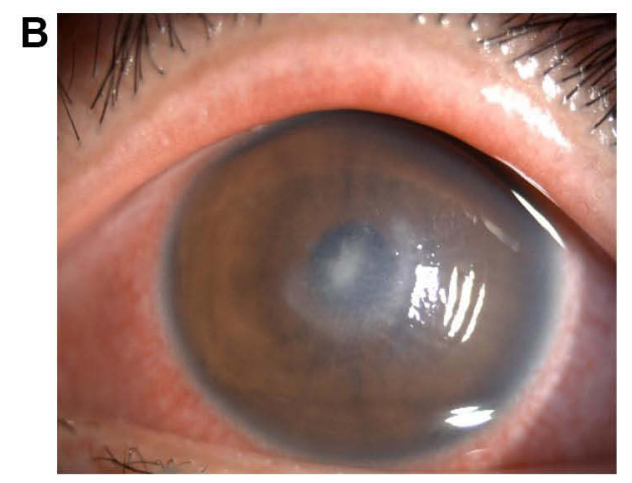

Figure I Slit-lamp examination revealed that the cornea of the right eye (A) was transparent, the upper corneal epithelium was poorly healed, and the anterior chamber was normal. (B) In the left eye, mixed congestion of the bulbar conjunctiva, corneal edema, and white infiltrating foci with crab-like changes with unclear boundaries of approximately $2 \times 3 \mathrm{~mm}^{2}$ in the center, unclear lesion boundaries with annular reaction ring, corneal endodermis and Descemet's folds radially perpendicular to the lesion, and sediments adhering to endodermis were observed.

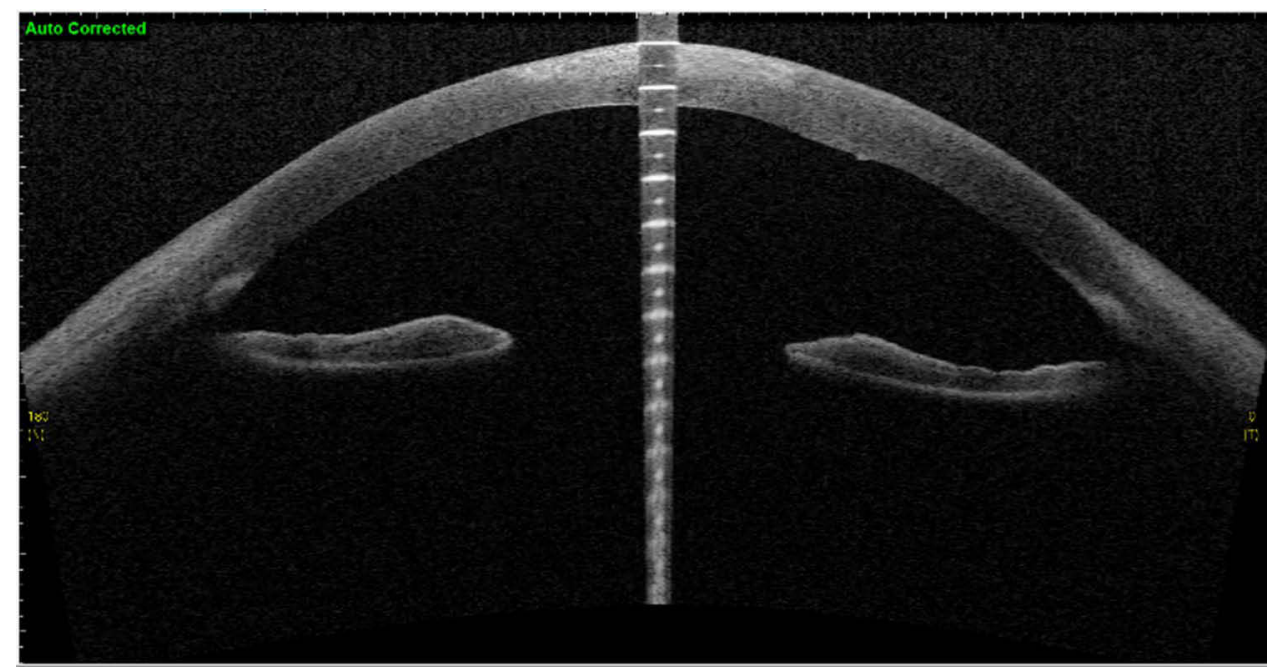

Figure 2 Oct-optic (cassia) examination of the left eye revealed that the central cornea was swollen and cloudy up to a $1 / 2$ depth. 

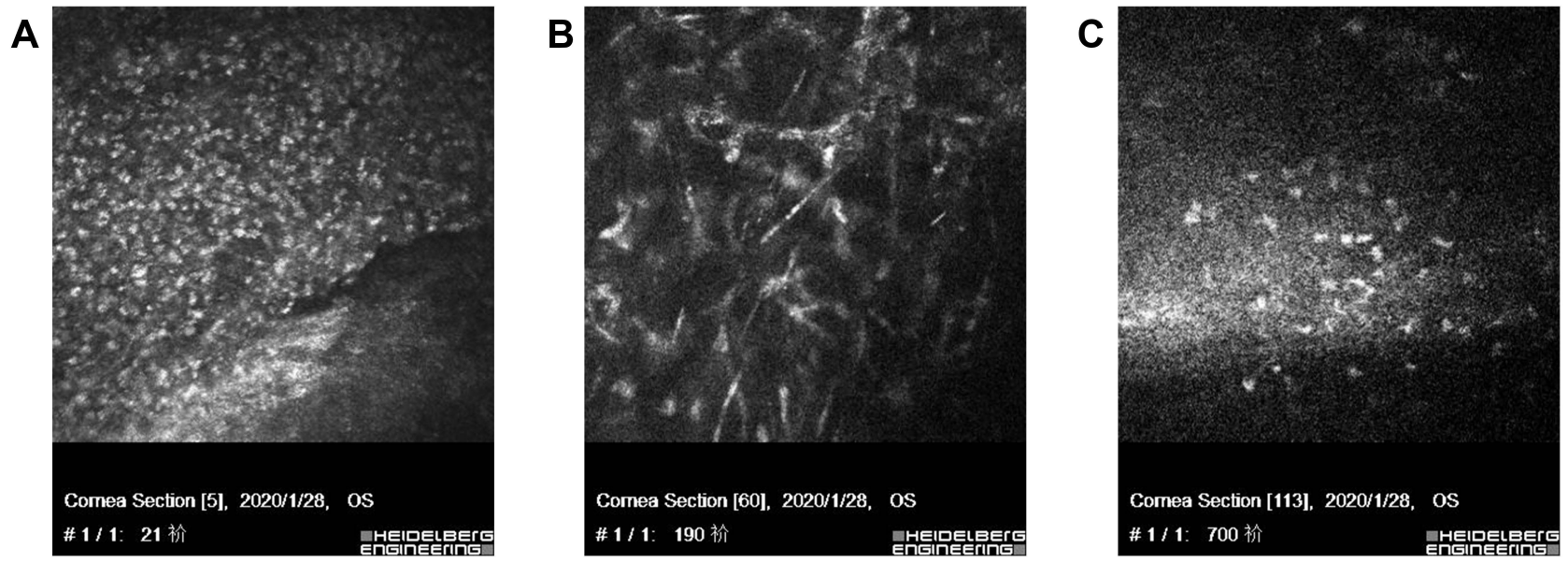

Figure 3 Confocal microscopy of the left eye revealed that epithelial cells at the lesion site were necrotic and absent (A), with a large number of inflammatory cells infiltrating the superficial stromal layer (B). Turbidity and edema of the stromal layer, blurred endothelium, and highly reflective particles attached to corneal endodermis were also observed $(\mathbf{C})$.

blurred, with a large number of inflammatory cells infiltrating the superficial stromal layer (Figure 3B) and highly reflective particles attaching to the corneal endodermis (Figure 3C). The corneal scraping results were negative. Microscopic examination with Giemsa staining on the conjunctival sac smear showed many neutrophils and few diplococci (Figure 4). Infectious keratitis in the left eye and poor epithelial healing in the right eye after trans-PRK were considered. Based on the accessory examination above, we selected antibiotics treatment for the left eye and the wait-and-see approach for the right eye. To be specific, the left eye was treated with $0.5 \%$ levofloxacin eye drops every 30 minutes, cefazolin sodium eye drops every 30 minutes, and gatifloxacin gel 1 time each night. After 3-day treatment, the patient's symptoms were relieved,

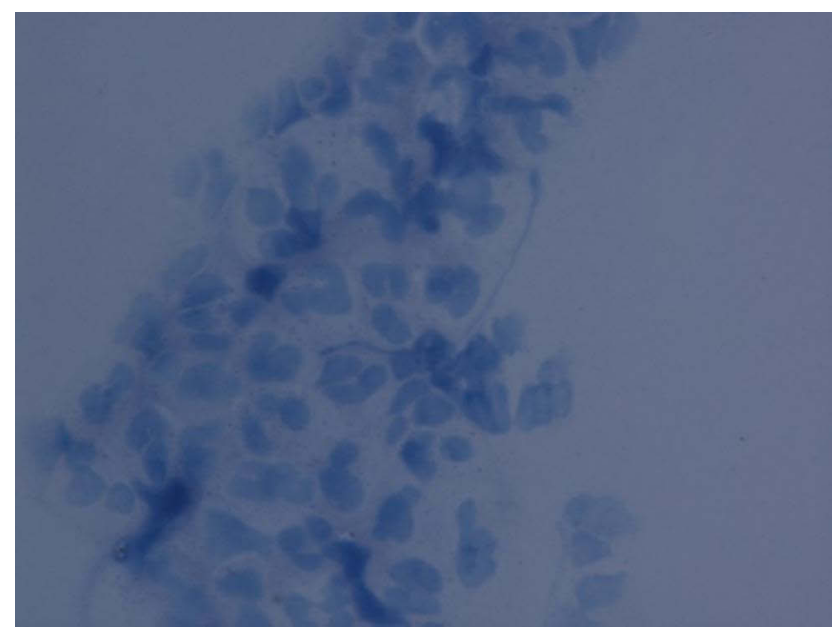

Figure 4 Microscopic examination with Giemsa staining on the conjunctival sac smear revealed more neutrophils and a small number of diplococci. and the lesions were decreased macroscopically. At the same time, corneal scraping specimen culture results indicated large numbers of white and flat colony by blood AGAR plate at $37^{\circ} \mathrm{C}$ for 36 hours (Figure 5). Gram-positive cocci, doublepermutation or short chain-like permutation, negative thixoenzyme, and non- $\beta$-hemolysis were found via microscopy (Figure 6). The organism was further identified as Gemella haemolysans using the DL-96 Strep test (ZHUHAI DL BIOTECH. CO. CTD). Drug sensitivity tests revealed that it was susceptible to quinolones, aminoglycosides, $\beta$-lactamase, oxazolone, and polypeptide antibiotics. The infection was controlled after 1-week treatment with the above regimen. And the reductive doses were applied after then. Particularly, the patient received $0.5 \%$ levofloxacin eye drops every 1 hour, lincomycin eye water every 1 hour, and $0.02 \%$ flomilone eye drops 4 times a day. One month after the operation, infection of the left eye was under control, and the nubecula remained in the center of the cornea (Figure 7). His visual acuities of the left and right eyes were 12/20 and 24/20.

This case has obtained the consent of Henan Provincial People's Hospital and the patient, and the patient has signed the informed consent for the release of relevant details in the case, such as examination results, pictures, etc.

\section{Discussion}

Infectious keratitis is a serious complication after refractive surgery. Early postoperative corneal surface surgery due to the absence of the corneal epithelial barrier may increase the risk of postoperative infection. According to the previous reports, the incidence of postoperative infection after LASIK was $0.035 \%$, while the incidence after 


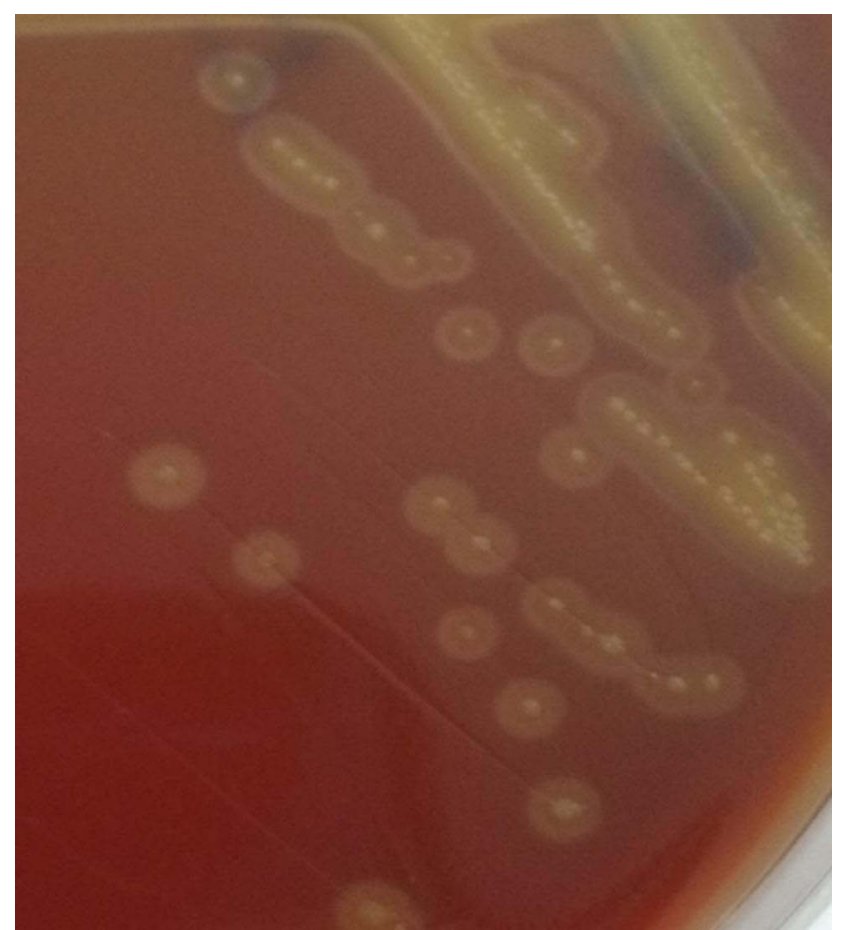

Figure 5 Corneal scraping specimen culture by blood agar plate at $37^{\circ} \mathrm{C}$ for 36 hours. A large number of white, flat, slightly protruding, dry colonies were observed, with smooth, translucent surface and viridans hemolysis.

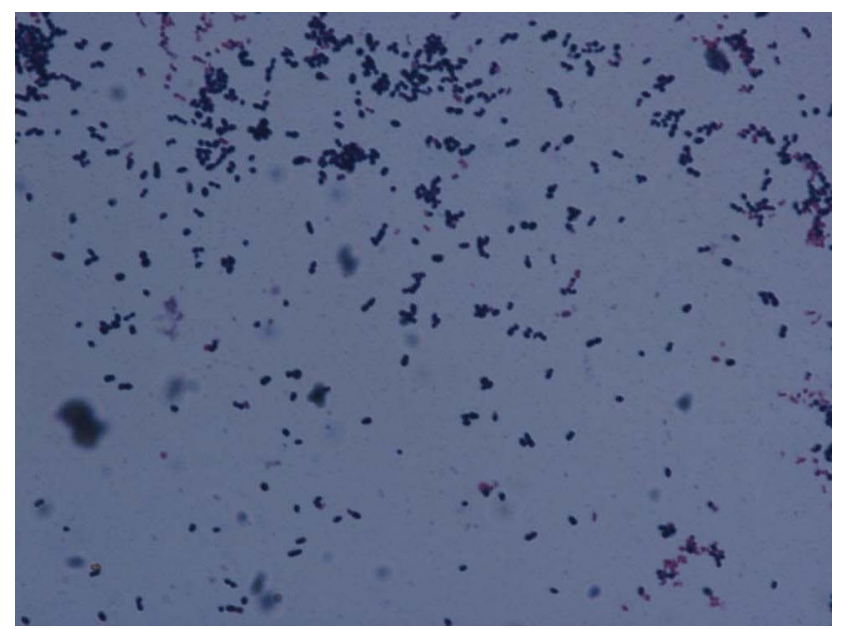

Figure 6 Gram-positive cocci, double-permutation or short chain-like permutation, negative thixoenzyme, and non- $\beta$-hemolysis were observed via microscopy.

surface surgery was $0.200 \% .{ }^{6}$ Bacteria, including staphylococcus, pneumococcus and mycobacterium, is the most common pathogenic microorganism of corneal postoperative infection. ${ }^{7-10}$ There have been no reports about Gemella haemolysans bacterial keratitis after the corneal refractive surgery.

The Gemella genus is characterized by thixozyme negative, facultatively anaerobic and gram-positive cocci that can

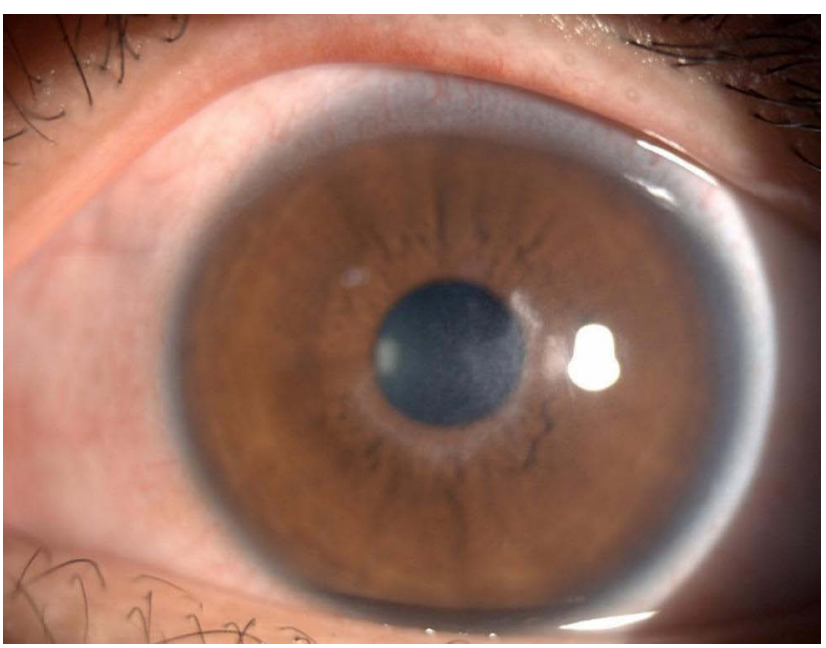

Figure 7 One month after the operation, the left eye infection was under control, and the nubecula remained in the center of the cornea.

be arranged in pairs, quadruplets or short chains. At present, the genus includes G. haemolysans, G. mobillorum, G. palaticanis, G. sanguinis, and G. bergeriae ${ }^{11,12}$. Among them, G. haemolysans is a gram-positive coccus, with easily decolorized but not powerful.

After 48 hours of culture on a blood agar plate, small, round and neat colonies with grass green hemolysis rings but no pigment could be formed. The optimal growth temperature of the bacteria is $37^{\circ} \mathrm{C}$, thus it could easily grow in the human body. It is a normal colonizing bacteria of the upper respiratory tract, gastrointestinal tract and urogenital tract and can cause opportunistic infection.

Previous reports indicated that invasive infections caused by $G$. haemolysans included infective endocarditis, osteoarthrosis, peritonitis, endophthalmitis, bacteremia, meningitis, and brain abscess. And it was popular among the individuals with immunodeficiency, diabetes, alcohol addiction or bad dentin, ${ }^{13-18}$ a total of 10 cases of ophthalmic G. haemolysans infection have been reported ${ }^{19-28}$ (Table 1), and 4 of them were endophthalmitis, including 2 cases of endophthalmitis caused by G. haemolysans after phacoemulsification. ${ }^{19,20}$ And 1 case was delayed acute endophthalmitis caused by G. haemolysans after trabeculectomy. ${ }^{21}$ The other case of severe endophthalmitis caused by $G$. haemolysans infection after intravitreal injection of ranibizumab. ${ }^{22}$ One case of posttraumatic endophthalmitis caused by G. haemolysans, ${ }^{23}$ who was one of the cases in a prospective study on 17 eyes with posttraumatic endophthalmitis from 2004 to 2010, which was mixed infection caused by Streptococcus salivarius and G. haemolysans. There were 2 cases of canaliculitis caused by G. haemolysans. ${ }^{24,25}$ A total of 3 cases had keratitis similar 
Table I Previously Reported Cases of Ocular Infection Caused by Gemella heamolysans

\begin{tabular}{|c|c|c|c|c|c|}
\hline Author & $\begin{array}{c}\text { Year of } \\
\text { Publication }\end{array}$ & $\begin{array}{l}\text { Secondary } \\
\text { Infection }\end{array}$ & $\begin{array}{l}\text { Intravitreal } \\
\text { Ranibizumab } \\
\text { Injection }\end{array}$ & Treatment Measures & $\begin{array}{c}\text { Length of } \\
\text { Treatment } \\
\text { After Diagnosis }\end{array}$ \\
\hline Raman et al ${ }^{19}$ & 2003 & Endophthalmitis & $\begin{array}{l}\text { Cataract surgery and } \\
\text { sarcoidosis }\end{array}$ & Ciprofloxacin & 2 months \\
\hline Nalamad et $\mathrm{al}^{20}$ & 2010 & Endophthalmitis & Cataract surgery & $\begin{array}{c}\text { Vancomycin, ceftazidime, } \\
\text { dexamethasone, ciprofloxacin } \\
\text { and cefazolin }\end{array}$ & 4 weeks \\
\hline Sawada et $\mathrm{al}^{21}$ & 2009 & Endophthalmitis & Trabeculectomy & Ceftazidime and vancomycin & Unknown \\
\hline Salceanu et $\mathrm{al}^{22}$ & 2017 & Endophthalmitis & $\begin{array}{l}\text { Intravitreal ranibizumab } \\
\text { injection }\end{array}$ & $\begin{array}{l}\text { Vancomycin, amikacin and } \\
\text { levofloxacin }\end{array}$ & I month \\
\hline Pierre-LoÏc Cornut et al ${ }^{28}$ & 2004-2010 & Endophthalmitis & Post-traumatic & Unknown & Unknown \\
\hline Sen et $\mathrm{al}^{24}$ & 2015 & Canaliculitis & Unknown & Unknown & Unknown \\
\hline Romero-Trevejo et $\mathrm{al}^{25}$ & 2018 & $\begin{array}{l}\text { Acute primary } \\
\text { canaliculitis }\end{array}$ & Old woman & $\begin{array}{l}\text { Tobramycin and } \\
\text { dexamethasone }\end{array}$ & I4 days \\
\hline Ritterband et $\mathrm{al}^{26}$ & 2002 & $\begin{array}{l}\text { Keratitis with } \\
\text { consecutive } \\
\text { endophthalmitis }\end{array}$ & $\begin{array}{l}\text { Sarcoidosis treated } \\
\text { chronically with } \\
\text { systemic prednisone }\end{array}$ & $\begin{array}{l}\text { Ciprofloxacin, vancomycin and } \\
\text { prednisolone acetate }\end{array}$ & 6 weeks \\
\hline Elmallah et $\mathrm{al}^{27}$ & 2006 & $\begin{array}{l}\text { Crystalline } \\
\text { keratopathy }\end{array}$ & Penetrating keratoplasty & $\begin{array}{l}\text { Loteprednol etabonate and } \\
\text { gatifloxacin }\end{array}$ & 3 months \\
\hline Kailasanathan et $\mathrm{al}^{23}$ & 2007 & $\begin{array}{l}\text { Crystalline } \\
\text { keratopathy }\end{array}$ & Penetrating keratoplasty & $\begin{array}{c}\text { Vancomycin, cefuroxime and } \\
\text { ofloxacin }\end{array}$ & Unknown \\
\hline
\end{tabular}

to this case, including 2 cases of keratitis and 1 case of keratitis complicated with endophthalmitis caused by G. haemolysans. One case of keratitis caused by long-term use of glucocorticoids, which failed to respond to drug treatment and developed into endophthalmitis. G. haemolysans was cultured in cornea, aqueous fluid and vitreous of the patient. ${ }^{26}$ The other case report was an amebic keratitis caused by long-term wearing of RGP underwent penetrating keratoplasty after the failure of anti-amebic drug therapy. The epithelium was poorly healed for a long time after surgery, and various treatments failed. G. haemolysans was cultured from corneal spatula examination half a year after surgery. In one case report, ${ }^{28}$ a patient with recurrent herpes simplex keratitis who underwent transdermal keratoplasty had a poor therapeutic response 18 months after surgery. Corneal biopsy was performed to produce $G$. haemolysans. These cases were in the clear pathogen, the application of effective antibiotics, such as levofloxacin, ciprofloxacin, ceftazidime and vancomycin, the disease was quickly controlled. Therefore, we speculate that G. haemolysans are normal colonizing bacteria in the conjunctival sac.
In our report, the patient received trans-PRK and first presented with severe eye pain on the 4th postoperative day. Slit-lamp and confocal microscopy examination revealed that cornea of the left eye was in a state of acute inflammation. A large number of bacteria were found after corneal sample cultures were grown. The organism was further identified as G. haemolysans using a Mini API Rapid ID 32 Strep test. Afterwards, drug sensitivity was tested. Literature reports indicated that G. haemolysans was sensitive to penicillin, ampicillin, rifampicin, vancomycin and other antimicrobial agents but had low resistance to aminoglycosides and trimethoprimidine. $^{29}$ Reed et $\mathrm{al}^{30}$ cultivated penicillinresistant G. haemolysans, and the resistance of the strain to vancomycin, tekranin, erythromycin and tetracycline was significantly increased. The differences among the results of these studies may be related to the diverse susceptibilities of different strains to drugs and the emergence of drug resistance at various times. Therefore, in the early stage of infection, multiple antibiotics should 
be used in combination. After the results of drug sensitivity testing, the drug should be adjusted according to the effect of the original treatment combined with the results of drug sensitivity testing. In addition to local treatment, a combination of systemic use is required for severe infections. In this case, topical administration of the sensitive antibiotics levofloxacin, amikacin, cefazolin sodium eye drops, and gatifloxacin eye gel resulted in rapid infection control. After the rational use of corticosteroids to reduce the formation of corneal scar, good results were finally achieved.

This article is the first to report a case of G. haemolysans keratitis after trans-PRK and the fourth case of G. haemolysans corneal infection. G. haemolysans keratitis infections usually occur in patients with low immunity or corneal surgery. Its clinical manifestations include corneal central white infiltration characteristic lesions, a crab claw appearance change or crystal change, and unclear focal boundary and can be accompanied by a reaction ring. Corneal Descemet's and endodermis folds radially perpendicular to the lesion may be accompanied by severe anterior chamber reactions, hypopyon, and even endophthalmitis. Gram-positive cocci can be found on corneal smear test, and the diagnosis depends on the results of culture identification. Most studies have shown that this bacterium is sensitive to vancomycin and quinolones, which can be used as the preferred drugs. Due to the different susceptibilities of different strains to drugs, multiple antibiotic combinations can be used.

In recent years, trans-PRK has been widely used in the clinic due to its advantages. However, it is necessary to guard against the occurrence of corneal infection caused by incomplete healing of the corneal epithelium in the early postoperative period and the application of glucocorticoids. Patients in the early postoperative period should be followed up closely. Once a patient is suspected of corneal infection, the lesion should be carefully observed to evaluate the nature of the infection. Oct-examination of the anterior segment can conduce to determine the depth and scope of the lesion. Confocal microscopy is helpful to determine the nature of the infection. Corneal lesion smear examination and bacterial culture are conducive to diagnose disease, and drug sensitivity tests have important effects on the treatment of diseases.

\section{Disclosure}

The authors report no conflicts of interest in this work.

\section{References}

1. Adib-Moghaddam S, Soleyman-Jahi S, Salmanian B, et al. Singlestep transepithelial photorefractive keratectomy in myopia and astigmatism: 18-month follow-up. J Cataract Refract Surg. 2016;42 (11):1570-1578. doi:10.1016/j.jcrs.2016.08.029

2. Netto MV, Mohan RR, Sinha S, Sharma A, Dupps W, Wilson SE. Stromal haze, myofibroblasts, and surface irregularity after PRK. Exp Eye Res. 2006;82(5):788-797. doi:10.1016/j.exer.2005.09.021

3. Förster W, Becker K, Hungermann D, Busse H. Methicillin-resistant Staphylococcus aureus keratitis after excimer laser photorefractive keratectomy1. J Cataract Refract Surg. 2002;28(4):722-724. doi:10.1016/s0886-3350(01)01076-8

4. Donnenfeld ED, O'Brien TP, Solomon R, Perry HD, Speaker MG, Wittpenn J. Infectious keratitis after photorefractive keratectomy. Ophthalmology. 2003;110(4):743-747. doi:10.1016/s0161-6420(02) 01936-x

5. Li Y, Wang Y. Chinese expert consensus on perioperative medication in laser corneal refractive surgeries (2019). Chin Med Sci J. 2020;35 (1):1-12. doi:10.24920/003712

6. Ortega-Usobiaga J, Llovet-Osuna F, Djodeyre MR, Llovet-Rausell A, Beltran J, Baviera J. Incidence of corneal infections after laser in situ keratomileusis and surface ablation when moxifloxacin and tobramycin are used as postoperative treatment. J Cataract Refract Surg. 2015;41(6):1210-1216. doi:10.1016/j.jcrs.2014.09.041

7. Chang MA, Jain S, Azar DT. Infections following laser in situ keratomileusis: an integration of the published literature. Surv Ophthalmol. 2004;49(3):269-280. doi:10.1016/j.survophthal.2004.02.007

8. Woodward M, Randleman JB. Bilateral methicillin-resistant Staphylococcus aureus keratitis after photorefractive keratectomy. $J$ Cataract Refract Surg. 2007;33(2):316-319. doi:10.1016/j. jcrs.2006.08.060

9. Kymionis GD, Diakonis VF, Bouzoukis DI, Lampropoulou I, Pallikaris AI. Idiopathic recurrence of diffuse lamellar keratitis after LASIK. J Refract Surg. 2007;23(7):720-721. doi:10.3928/1081597X-20070901-12

10. Asbell PA. Valacyclovir for the prevention of recurrent herpes simplex virus eye disease after excimer laser photokeratectomy. Trans Am Ophthalmol Soc. 2000;98:285-303.

11. Rryn A. Genus Gemella berger. In: Sneath PR, editor.Bergey's Manual of Systematic Bacteriology.Vol.2. Baltimore, MD:Williams and Wilkins;1999:1081-1082.

12. Kilpper-Balz R, Schleifer K. Transfer of Streptococcus morbillorum to the Genus Gemella as Gemella morbillorum comb. nov. Int $J$ Syst Bacteriol. 1988;38(4):442-443. doi:10.1099/00207713-38-4-442

13. Kaufhold A, Franzen D, Lütticken R. Endocarditis caused by Gemella haemolysans. Infection. 1989;17(6):385-387. doi:10.1007/ bf01645552

14. Liu D, Bateman T, Carr E, Foster P. Endocarditis due to Gemella haemolysans in a newly diagnosed multiple myeloma patient. J Community Hosp Intern Med Perspect. 2016;6(4):32357. doi:10.3402/jchimp.v6.32357

15. Fangous MS, Hémon F, Graf $P$, et al. Bone infections caused by Gemella haemolysans. Med Mal Infect. 2016;46(8):449-452. doi:10.1016/j.medmal.2016.06.005

16. Rose B, Jeer PJ, Spriggins AJ. Gemella haemolysans infection in total hip arthroplasty. Case Rep Orthop. 2012;2012:691703. doi: $10.1155 / 2012 / 691703$

17. Woo PC, Lau SK, Fung AM, Chiu SK, Yung RW, Yuen KY. Gemella bacteraemia characterised by $16 \mathrm{~S}$ ribosomal RNA gene sequencing. J Clin Pathol. 2003;56(9):690-693. doi:10.1136/jcp.56.9.690

18. Galen BT, Banach DB, Gitman MR, Trow TK. Meningoencephalitis due to Gemella haemolysans. $J$ Med Microbiol. 2014;63(Pt 1):138-139. doi:10.1099/jmm.0.063347-0 
19. Raman SV, Evans N, Freegard TJ, Cunningham R. Gemella haemolysans acute postoperative endophthalmitis. $\mathrm{Br} J$ Ophthalmol. 2003;87(9):1192-1193. doi:10.1136/bjo.87.9.1192-a

20. Nalamada S, Jalali S, Reddy AK. Acute postoperative endophthalmitis by Gemella haemolysans. Indian $J$ Ophthalmol. 2010;58 (3):252-253. doi:10.4103/0301-4738.62658

21. Sawada A, Mochizuki K, Katada T, et al. Gemella species-associated late-onset endophthalmitis after trabeculectomy with adjunctive mitomycin C. J Glaucoma. 2009;18(6):496-497. doi:10.1097/ IJG.0b013e31818c6f07

22. Salceanu SO, Levy S, Cunningham R, Frimpong-Ansah K. Severe Gemella haemolysans endophthalmitis following ranibizumab intravitreal injection. Indian J Ophthalmol. 2017;65(11):1249-1251. doi:10.4103/ijo.IJO_1007_16

23. Kailasanathan A, Anderson DF. Infectious crystalline keratopathy caused by Gemella haemolysans. Cornea. 2007;26(5):643-644. doi:10.1097/ICO.0b013e3180439c0c

24. Sen E, Evren E, Elgin U. Canaliculitis due to Gemella Haemolysans and Porphyromonas asaccarolytica. Gazi Med J. 2015;26:183-184. doi:10.12996/gmj.2015.54
25. Romero-Trevejo JL, Somavilla-Lupiáñez J. Canaliculitis due to Gemella haemolysans in a single isolate [Canaliculitis por Gemella haemolysans en aislamiento único]. Arch Soc Esp Oftalmol. 2018;93 (6):307-309. doi:10.1016/j.oftal.2017.08.006

26. Ritterband D, Shah M, Kresloff M, Intal M, Shabto U, Seedor J. Gemella haemolysans keratitis and consecutive endophthalmitis. Am JOphthalmol. 2002;133(2):268-269. doi:10.1016/s0002-9394(01)01271-5

27. Elmallah MK, Munir WM, Janda WM, Tu EY. Gemella haemolysans infectious crystalline keratopathy. Cornea. 2006;25(10):1245-1247. doi:10.1097/01.ico.0000240090.44195.a3

28. Cornut PL, Youssef El B, Bron A, et al. A multicentre prospective study of post-traumatic endophthalmitis. Acta Ophthalmol. 2013;91 (5):475-482. doi:10.1111/j.1755-3768.2011.02349.x

29. Buu-Hoï A, Sapoetra A, Branger C, Acar JF. Antimicrobial susceptibility of Gemella haemolysans isolated from patients with subacute endocarditis. Eur J Clin Microbiol. 1982;1(2):102-106. doi:10.1007/ bf02014200

30. Reed C, Efstratiou A, Morrison D, Woodford N. Glycopeptideresistant Gemella haemolysans from blood. Lancet. 1993;342 (8876):927-928. doi:10.1016/0140-6736(93)91975-r
Infection and Drug Resistance

\section{Publish your work in this journal}

Infection and Drug Resistance is an international, peer-reviewed openaccess journal that focuses on the optimal treatment of infection (bacterial, fungal and viral) and the development and institution of preventive strategies to minimize the development and spread of resistance. The journal is specifically concerned with the epidemiology of
Dovepress

antibiotic resistance and the mechanisms of resistance development and diffusion in both hospitals and the community. The manuscript management system is completely online and includes a very quick and fair peerreview system, which is all easy to use. Visit http://www.dovepress.com/ testimonials.php to read real quotes from published authors. 